Special Article

\title{
'The Health of the Nation': the impact of personality disorder on 'key areas'
}

\author{
K.R.W. Norton \\ Henderson Hospital, Sutton, Surrey, and Section of Forensic Psychiatry, Department of Mental Health \\ Sciences, St George's Hospital Medical School, London, UK
}

\begin{abstract}
Summary: The purpose of this response paper is to document a form of mental illness, namely, personality disorder: (1) whose impact is far-reaching, impinging on different 'key areas' identified in 'The Health of the Nation' (The Health of the Nation: A Consultative Document. HMSO, London, 1991), including: eating and drinking habits, smoking, prevention of accidents, human immunodeficiency (HIV)/ acquired immunodeficiency syndrome (AIDS), and other mental illness itself; (2) which tends to be underdiagnosed by health-care professionals in spite of its aetiological relationship to other 'key areas' (as above); (3) which tends to be associated with negative therapeutic attitude in spite of well-documented, albeit specialist, treatment expertise; (4) which, importantly, transmits psychopathology from one generation to the next and hence has a pivotal role to play in prevention; and (5) which, for the reasons enumerated above, could form a 'target' for various, measurable, interventions.
\end{abstract}

\section{Personality disorder}

Personality disorder is defined by the International Classification of Diseases, 9 th revision ${ }^{1}$ as: 'Deeply ingrained maladaptive patterns of behaviour generally recognisable by the time of adolescence or earlier and continuing throughout most of adult life, but often becoming less obvious in middle or old age. Personality is abnormal either in the balance of its components, their quality and expression or in its total aspect. Because of this deviation or psychopathy the patient suffers or others have to suffer and there is an adverse effect upon the individual or on society. This includes what is sometimes called psychopathic personality, but if it is determined primarily by malfunctioning of the brain, the issue should not be classified here but as one of the non-psychotic organic brain syndromes ...' Other classificatory schemas tend to use very similar criteria, for example, Diagnostic and Statistical Manual of Mental Disorders (3rd ed). ${ }^{2}$ Subcategorization of personality disorders is unreliable especially where the condition is severe. ${ }^{3,4}$

Correspondence: K.R.W. Norton, M.A.(Cantab.), M.B., B.Chir., M.D., M.R.C.Psych., Henderson Hospital, 2 Homeland Drive, Brighton Road, Sutton, Surrey SM2 5LT, UK.

Accepted: 9 December 1991

\section{Prevalence of personality disorder}

Reported prevalence rates vary, but there i accumulating evidence for a prevalence of approximately $10 \%$ of the total population suffering from personality disorder. ${ }^{5,6}$ Other research has identified a gradient within the referral system to psychiatrists. $^{7}$ Thus prevalence is increased in general practitioner (GP) attenders (approximately $20 \%$ ) and is greater in psychiatric out-patient attenders (approximately 30\%) and greatest in psychiatric in-patients (approximately 40\%). Corresponding data for prevalence of personality disorder in other medical conditions are lacking although it is known that the addictions (to illicit drugs, prescribed drugs, alcohol and tobacco) are all positively associated with personality disorder. Likewise, disorders of eating (anorexia nervosa, bulimia nervosa, and obesity) are all over-represented in personality disordered individuals. ${ }^{8-11}$ The sexual behaviour of personality disordered individuals is also abnormal spanning the perversions ${ }^{12}$ and also including sexual victimization, for example, rape and child sexual abuse. ${ }^{13}$

\section{Reporting of personality disorder patients' statistics}

Personality disorder, as a primary diagnosis, represents $8.4 \%$ of first psychiatric in-patient admissions in the UK and $7.2 \%$ of all admissions to mental hospitals (Health and Personal Social Ser- 
vice Statistics). Since secondary diagnoses are seldom reliably coded, the above figures represent an under-estimate of the true rates of personality disorder in such populations. A recently cited study ${ }^{7}$ found that the reported rate of personality disorder increased from 15 to $50 \%$ once all psychiatric in-patients were screened for a personality disorder diagnosis.

\section{Co-morbidity}

The co-existence of personality disorder with other symptom disorder diagnoses, such as schizophrenia, manic-depressive psychosis and neurosis, is not solely of academic interest. It is associated with poorer treatment response and longer, hence more costly, treatment. ${ }^{7}$ The effect of personality disorder on the treatment of medical conditions is not known. It is likely, however, that compliance with treatment will be impaired, as will be taking up of medical advice. The end result is a poorer cost-benefits analysis.

\section{Aetiology of personality disorder}

There is no single cause of personality disorder. Aetiology is multifactorial and there are substantial associations between later personality disorder and childhood influences such as poor supervision, parental uninvolvement, parental criminality and aggressiveness, composite family handicap and deviant peers. ${ }^{14,15}$ There is also a positive association between personality disorder and previous child sexual abuse ${ }^{16}$ and alcohol and drug misuse in parents. ${ }^{17}$ Aetiological agents act particularly via disturbed relationships with close family members during the formative years of the personality. These effects act mainly through long-term repeated influences rather than a single traumatic event. In this way, personality-disordered parents produce personality-disordered children. Although difficult to quantify, the genetic contribution to this familial transmission of psychopathology is likely to be small. ${ }^{18}$

\section{Personality disorder as a determinant of health care-seeking behaviour}

Many patients suffering from moderate to severe personality disorder have little tolerance of anxiety or other psychic (or physical) pain. They tend to present for help in crisis, often dramatically. The distortion of their personalities, being the result of influences acting in childhood and adolescence (as described above), is such as to impair their capacity to trust authority figures including doctors and nurses. ${ }^{19}$ This mistrust is rooted in a profoundly low self-esteem. One result is that harm, misfortune or illness is experienced as being deserved. Another outcome is that any real help provided is experienced as not merited. Hence compliance with treatment is poor. The end result is more episodes of incomplete treatment, hence poorer outcome and decreased cost-benefits. ${ }^{20}$

Personality-disordered patients attempt to find ways of dealing with psychic pain or of bolstering poor self-esteem which centre on various maladaptive strategies - all of which may be also damaging (directly or indirectly) or others who come into relation to them. ${ }^{21}$ Such strategies include shortterm anxiety reduction by illicit or prescribed (for example, benzodiazepine) drug misuse, alcohol dependence, eating disorders (anorexia nervosa, bulimia nervosa, obesity), tobacco smoking and sexual disinhibition (including prostitution and promiscuity). As well as the above strategies resulting in psychological damage or abuse of others, there is an associated physical abuse (both deliberate and via neglect) and an increased risk of HIV/AIDS, on account of the sexual disinhibition and drug misuse.

\section{Engagement in treatment}

Not surprisingly, personality-disordered patients are difficult to engage in treatment. Their presentation to professionals is often with a self-damaging act (overdose, wrist-slashing, burning) or else via an act of delinquency (theft, violence) rather than by the presentation of a symptom such as depression or anxiety. To an extent, the traditional medical model demands a 'symptom' as a sine qua non for treatment. Thus many clinicians feel disempowered, professionally, by personality-disordered patients who do not produce such an 'entry ticket'. Failure of the clinical encounter can lead to the maintenance of patients' mistrust of authority figures, on the one hand, and therapeutic nihilism from clinicians, on the other. ${ }^{22}$

The first therapeutic challenge, therefore, is to facilitate the personality-disordered individual in becoming a patient, that is, a person who is capable of verbalizing a complaint or symptom rather than expressing painful feelings solely via actions. 'Actions' do indeed speak louder than words but clinicians need to be able to delve below the level of actions (and indeed of symptoms) in order to address the underlying negative attitudes towards the self, which are at the root of the disorder of personality and which fuel the self-damaging and maladaptive behaviours. 


\section{Goals of treatment}

The goal of treatment is to convert the 'actor' into a 'thinker and feeler'. ${ }^{23}$ For this to be achieved, patients with personality disorder need to take on responsibility for their own actions rather than devolving this to professionals upon whom they often become overly dependent. Individual treatment approaches which are always more costly than group treatments, tend to founder partly because of the fostering of inappropriate dependency which militates against the owning of responsibility. Professionals are, confusingly, both idealized and denigrated. For personality disordered patients the power imbalance implied by the helper-helped relationship is particularly difficult to bear and their response to this is often a sabotaging of treatment.

\section{Group treatments}

After World War II, group-based treatment in psychiatry proliferated in the $\mathrm{UK}^{24-26}$ as a response to the increased number of psychological casualities resulting from the War action. Of the curative factors in group therapy, which have been extensively studied, ${ }^{27}$ a peer group aspect, providing opportunities for interpersonal learning, is prominent. Patients within group-based psychotherapeutic treatments are enabled to become dependent, not on an individual professional nor upon medication, but on the group comprising mainly nonprofessional members. ${ }^{28}$ The result is a decreased sense of alienation and an enhanced self-esteem breaking into the vicious circle which otherwise leads to difficulty asking for help, in a mature manner, using words.

\section{In-patient treatment programmes}

For the more severely ill personality disordered patients, in-patient programmes of treatment are required since out-patient approaches (whether individual or group) tend to fail. ${ }^{12}$ The approach adopted by Henderson Hospital, which was set up in 1947, has become a unique treatment resource for the in-patient treatment of personality disordered individuals, utilizing a 'therapeutic community' method. ${ }^{24,29,30}$ This approach involves no psychotropic medication, so lessening the potential for substitute dependence, but fosters more mature dependence on other people - initially in the form of fellow patients. Staff/patient hierarchy is diminished, yet present, and the emphasis is on a much more collaborative style of relationship rather than an authoritarian one. In this way clients' own personal resources are utilized to the full. The treatment approach has been shown to be successful both in alleviating personal distress, ${ }^{31}$ increasing self-esteem, ${ }^{32}$ and in decreasing psychiatric readmission and re-conviction rates. ${ }^{33,34}$

\section{Implications for 'The Health of the Nation' document}

(1) The above factors suggest a targeting of personality disorder since it is an invisible factor in the production of much ill-health (both mental and physical) including also the specific 'target areas' identified in the document. As such, personality disorder is an influence which can attack and undermine the Nation's health in a particularly poisonous way.

(2) The way in which personality disorder expresses itself makes it problematic to treat since engagement in treatment is impaired because many personality disordered patients do not 'complain' of symptoms but rather enact them, sometimes dramatically.

(3) The result of (2), above, is therapeutic pessimism in the minds of professionals who are often surprisingly ignorant of the factors which fuel deviant presenting behaviours and of the ways to harness the patient's own more healthy resources?

(4) The treatment setting of Henderson Hose pital represents one resource which has specialize in the treatment of personality-disordered individ? uals for over 40 years. Research findings records its beneficial impact on the outcome of such disorders.

\section{Possible targets}

\section{Recognition}

Given the prevalence of personality disorder (as indicated by research studies cited above), there is much unrecognized personality disorder in ordinary clinical practice which accounts for poor compliance and poor outcome of treatment for a wide variety of medical conditions. To increase the recognition of personality disorder, therefore, represents a credible target since its presence alone and its co-existence with other conditions contributes to a waste of important National Health Service resources. This target could be achieved via the launching of a suitable educational initiative to psychiatric and non-psychiatric medical personnel.

\section{Engagement}

Even when the true prevalance of personality disorder is recognized, therapeutic pessimism may remain and this would need to be countered by an educational programme targeted at health-care 
professionals (including those within psychiatry itself) and focusing on the learning of skills to achieve meaningful engagement of personality disordered individuals in treatment.

\section{Specialist treatment}

Once skills for engaging personality-disordered patients in treatment are widespread, then, and only then, can treatment be undertaken to an appropriate degree given the prevalence of personality disorder in the UK population at large. For a substantial minority (the precise number of which cannot be accurately predicted at present) there will be a need for intensive, long-term (measured in months or years) in-patient psychotherapeutic treatment, for example, as represented by the Henderson Hospital model of treatment. An appropriate target, already calculated by the Royal College of Psychiatrists, ${ }^{35}$ would be one such inpatient treatment resource per Region in the UK.

\section{Range of treatment resources}

There is a range of severity of personality disorder which demands treatment of differing types and also differing levels of security of the treatment setting. Consequently there needs to be a range of

\section{References}

1. World Health Organisation. Manual of the Ninth Revision of the International Classification of Diseases (ICD-9). Geneva, WHO, 1978.

2. American Psychiatric Association. Diagnostic and Statistical Manual of Mental Disorders, 3rd ed. (DSM-III). Washington, APA, 1980.

3. Coid, J.N. Psychopathic disorders. Curr Opin Psychiatr 1990, 2: $750-756$

4. Grove, W.M. \& Tellegan, A. Problems in the classification of personality disorders. J Pers Dis 1991, 5: 31-41.

5. Zimmerman, M.\& Coryell, W. DSM-III Personality disorder diagnoses in a non-patient sample: demographic correlates and comorbidity. Arch Gen Psychiatr 1989, 46: 682-689.

6. Reich, J., Yates, W. \& Nduagaba, M. Prevalence of DSM-III personality disorders in the community. Social Psychiat Psychiatr Epidemiol 1989, 24: 12-16.

7. Tyrer, P. Personality Disorders: Diagnosis, Management and Treatment. Wright, London, 1988.

8. Cooper, J.L., Morrison, T.L., Bigman, O.L. et al. Bulimia and borderline personality disorder. Int J Eating Dis 1988, 7: 43-49.

9. Pope, H.G. Frankenburg, F.R., Hudson, J.I., Jonas, J.M. \& Yurgelun-Todd, D. Is bulimia associated with borderline personality disorder? A controlled study. J Clin Psychiat 1987, 48: 5 .

10. Gartner, A., Marcus, R., Halmi, K. \& Loranger, A.W. DSM III-R Personality disorders in patients with eating disorder. Am J Psychiat 1989, 146: 1585-1591.

11. Levin, A.P. \& Hyler, S.E. DSM-III personality diagnosis in bulimia. Compr Psychiat 1986, 27: 47-53. treatment provisions which span the existing range of resources: from the Special Hospitals and Regional Secure Units, at one end of the treatment spectrum; to in-patient psychotherapy units and through to community/out-patient psychiatric resources which properly merge with the Districtbased psychiatric and psychotherapy out-patient services. In order to produce the necessary 'targets', the ratio of the size of various treatment settings to one another would need to be formulated. This would then allow for more detailed calculations to be carried out.

\section{Comment}

The above goals and objectives could be included within the 'target' of re-aligning resources which might accrue from the closure of the remaining 90 large psychiatric hospitals as indicated in The Health of the Nation. However, given the farreaching influence of personality disorder on aspects of health which are not strictly 'psychiatric', it might be that consideration of sources of funding for the above possible targets (recognition; engagement; and treatment) also includes nonpsychiatric sources.

12. Kernberg, O.F. Severe Personality Disorders: Psychotherapeutic Strategies. Yale University Press, New Haven, CT, 1984 .

13. Russell, D.E.H. The incidence and prevalence of intrafamilial and extrafamilial sexual abuse of female children. Child Abuse Neglect 1983, 7: 133-146.

14. Loeber, R. Development and risk factors of juvenile antisocial behaviour and delinquency. Clin Psychol Rev 1990, 10, $1-41$.

15. Paris, J. \& Frank, H. Perceptions of parental bonding in borderline patients. Am J Psychiat 1989, 11: 1498-1499.

16. Herman, J.L., Perry, C. \& Can der Kolk, B.A. Childhood trauma in borderline personality disorder. Am J Psychiat 1989, 146: 490-495.

17. Lewis, C.E. \& Bucholz, K.K. Alcoholism, antisocial behaviour and family history. Br J Addiction 1991, 86: 177-194.

18. Widom, C.S. A tail on an untold tale: response to biological and genetic contributors to violence - Widom's Untold Tale. Psychol Bull 1991, 109: 130-132.

19. Gerstley, L, McLellan, T., Alterman, A., Woody, G.E., Luborsky, L. \& Prout, M. Ability to form an alliance with the therapist: a possible marker for prognosis in patients with anti-social personality disorder. Am J Psychiat 1989, 146: 508-512.

20. Perry, J.C., Lavori, P.W. \& Hoke, L. A Markove model for predicting levels of psychiatric service usage in borderline and anti-social personality disorders and bipolar type II affective disorder. Psychiat Res 1987, 21: 215-232.

21. Perry, J.C. \& Klerman, G.L. Clinical features of borderline personality disorder. Am J Psychiat 1980, 142: 15-21. 
22. Lewis, G. \& Appleby, L. Personality disorder: the patients psychiatrists dislike. Br J Psychiat 1988, 153: 44-49.

23. Masterson, J.F. Treatment of the Borderline Adolescent: $A$ Developmental Approach. Wiley, New York, 1972.

24. Main, T. The hospital as a therapeutic institution. Bull Menninger Clin 1946, 10: 66-68.

25. Bion, W.R. Experiences in Groups. London, Heinemann, 1961.

26. Foulkes, S.H. Therapeutic Group Analysis. Allen and Unwin, London, 1964.

27. Yalom, I.D. The Theory and Practice of Group Psychotherapy. Basic Books, New York, 1975.

28. Leszcz, M. Group psychotherapy with the characterologically difficult patient. Int J Group Psychother 1989, 39: 311-335.

29. Jones, M. Social Psychiatry. Tavistock Books, London, 1952.
30. Whiteley, J.S. The Henderson Hospital. Int J Therapeutic Commun 1980, 1: 38-58.

31. Dolan, B.M., Wilson, J. \& Evans, C.D.H. Therapeutic community treatment for personality disordered adults: a long term follow-up study. Paper presented at British Psychological Society London Conference, 1990.

32. Norris, M. Changes in patients during treatment at Henderson Hospital therapeutic community during 1977-1981. Br J Med Psychol 1983, 56: 135-143.

33. Whiteley, J.S. The response of psychopaths to a Therapeutic Community. Br J Psychiat 1970, 116: 517-529.

34. Copas, J.B. \& Whiteley, J.S. Predicting success in the treatment of psychopaths. Br J Psychiat 1976, 129: 388-392.

35. Royal College of Psychiatrists. The future of psychotherapy services. Psychotherapy Specialist Section Working Group. Psych Bull 1991, 15: 174-179. 